\title{
Propuesta de zonificación ecológica económica para la unidad hidrográfica de la quebrada Chucumayo - Huarochirí, Lima
}

Artículos originales: GEOGRAFÍA

Recibido: 25/09/2020

Aprobado: $13 / 10 / 2020$

Publicado: 05/02/2021

\author{
Juan Felipe Meléndez de la Cruz \\ Universidad Nacional Mayor de San Marcos \\ jmelendezd@unmsm.edu.pe
}

\section{RESUMEN}

La Unidad hidrográfica de la quebrada Chucumayo se caracteriza por los relieves de montañas, con un régimen hídrico típico de medios semiáridos. Los suelos para cultivos en limpio son escasos y se localizan en terrazas aluviales de la parte baja de la mencionada subcuenca. Mientras que en las montańas las laderas son muy inclinadas con suelos de origen coluvial y con vegetación xerofita o matorrales. Tradicionalmente, en esos espacios la población ha adaptado esos ecosistemas de montaña construyendo terrazas agrícolas. En algunos sectores de la partes alta o cabecera de la subcuenca se localizan pastos y lagunas que podrían conservarse y brindar un servicio ambiental (turismo, recarga hídrica o investigación científica).

De otra parte, la expansión de las áreas urbanas de la localidad de Matucana hacia la parte baja de la subcuenca de la quebrada Chucumayo, es un ejemplo más del proceso de urbanización que se desarrolla en el país.

El presente trabajo de Zonificación Ecológica Económica actualizado al año 2019 muestra las posibilidades de uso de suelo teniendo en cuenta criterios de sostenibilidad.

Palabras clave: Zonificación, uso de suelo, ecosistema, montaña, cuenca hidrográfica

\section{Proposal of Economic Ecological Zoning for the Hydrographic Unit of the Chucumayo Stream - Huarochiri, Lima}

\begin{abstract}
The Hydrographic Unit of the Chucumayo Stream is characterized by mountain reliefs, with a typical hydric regime of semi-arid environments. Soils for clean crops are scarce and are located in alluvial terraces in the lower part of the mentioned sub-basin. While in the mountains the slopes are very steep with soils of colluvial origin and with xerophytic vegetation or scrub. Traditionally, in these spaces, the population has adapted these mountain ecosystems by building agricultural terraces. In some sectors of the upper or head part of the sub-basin pastures and lagoons are located that could be conserved and provide an environmental service (tourism, water recharge or scientific research).

On the other hand, the expansion of the urban areas of the town of Matucana towards the lower part of the sub-basin of the Chucumayo stream is one more example of the urbanization process that is taking place in the country.

The present work of Economic Ecological Zoning updated to the year 2019 shows the possibilities of land use taking into account sustainability criteria.
\end{abstract}

KeYwords: Zoning, land uses, ecosystem, mountain, hydrographic basin 


\section{Introducción}

E n el Perú desde la entrada en vigor del Reglamento de Zonificación Ecológica Económica (ZEE), aprobada mediante el Decreto Supremo No 087-2004 el 16 de diciembre de 2004, se viene utilizando esa metodología para determinar la aptitud del territorio con la posibilidad de desarrollarlo en diferentes ámbitos territoriales y escalas espaciales.

Los trabajos de Zonificación Ecológica Económica (ZEE) se han convertido en uno de los principales insumos para ordenar un territorio mediante una planificación física. Sin embargo, existen pocos trabajos de ZEE a nivel de subcuenca, que puedan aportar en el conocimiento del medio físico, así como establecer la relación entre las actividades económicas que se realizan en la parte alta y baja de la referida unidad hidrográfica.
En ese sentido, se eligió la unidad hidrográfica de la quebrada de Chucumayo que se localiza aledaño a la localidad de Matucana, capital de la provincia de Huarochirí, departamento de Lima, como muestra relevante de los cambios de cobertura y usos de suelo en espacios tradicionalmente rurales. En el año 2014 se iniciaron los estudios de ZEE en la mencionada unidad hidrográfica. Durante el año 2019 se amplió la información sobre Capacidad de Uso Mayor de Suelos y se hizo un nuevo levantamiento de uso de suelo obteniéndose una Zonificación Ecológica Económica actualizada de la mencionada área de estudio.

El referido estudio (2019) viene acompañado de diez mapas temáticos: base, geología, geomorfología, pendientes, vegetación, usos de suelo, capacidad de uso mayor de suelos, unidades ecológicas (UE), unidades ecológicas económicas (UEE) y zonificación ecológica económica (ZEE). De otra parte, se organizó la información digital mediante un Geodatabase - GdB) compuesta de capas temáticas y de integración espacial.

Gráfico 1. Mapa Base

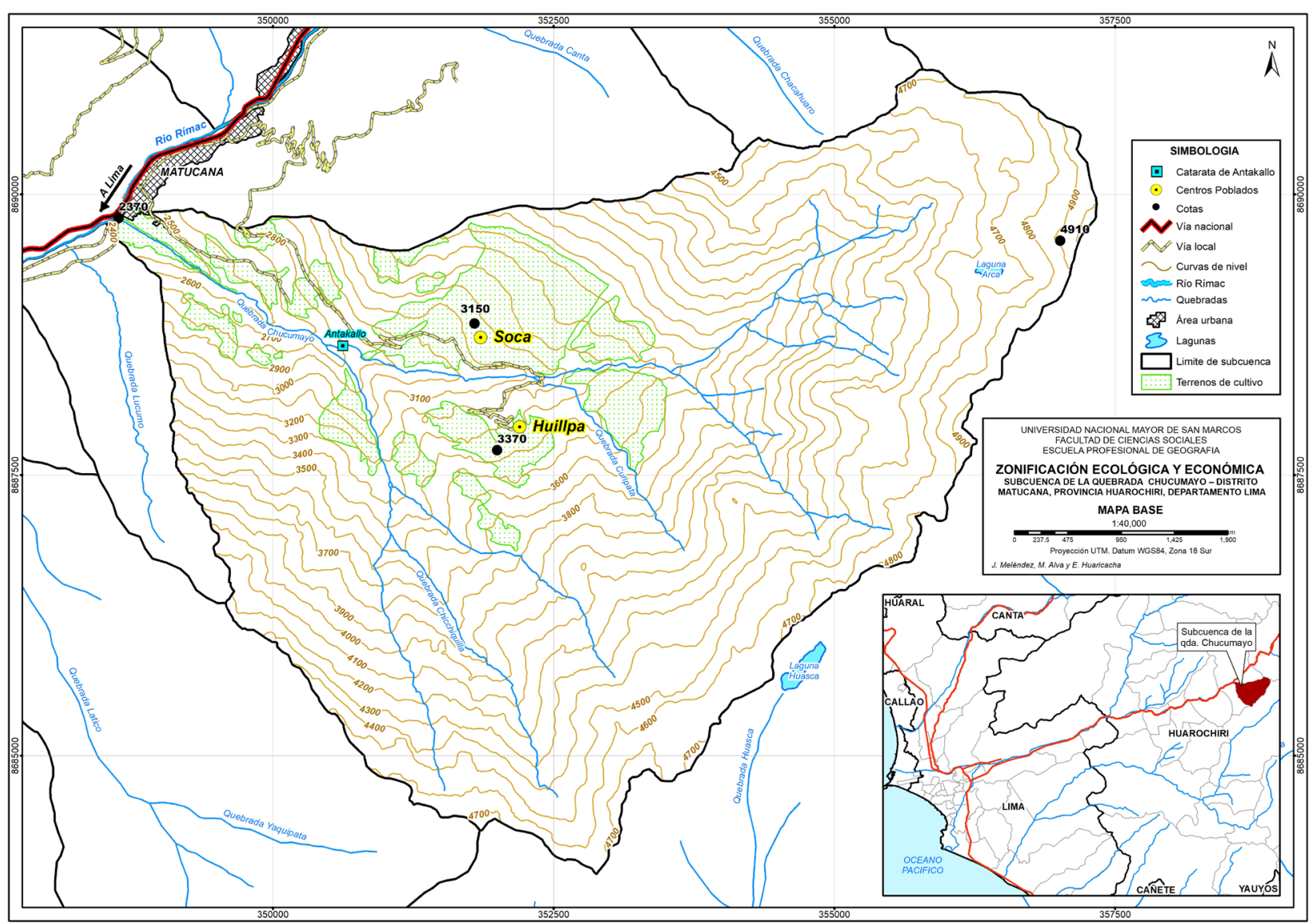

Elaboración propia. 


\section{Unidad hidrográfica}

La subcuenca de la quebrada de Chucumayo es una unidad hidrográfica que es un afluente del río Rímac por su margen izquierda, localizándose en la vertiente del Pacífico. La unidad hidrográfica de la quebrada Chucumayo tiene una superficie de $34.74 \mathrm{~km}^{2}$ y la corriente tiene una extensión de 9,200 metros y una pendiente promedio de $21^{\circ}$. La naciente o corriente de primer orden (sin afluentes) de la quebrada tiene una altitud cercana a los 5,000 m.s.n.m. y su nivel de base se encuentra aproximadamente a 2,350 m.s.n.m.

\section{Análisis de información temática}

\section{Geología}

La geología del área de estudio se enmarca en la consolidación del sistema plegado de los Andes desde el Cretácico incluyendo el Cuaternario. Con relación a la litología resalta el Grupo Rímac, formado por rocas volcano-sedimentarias que se extiende en gran medida en la mencionada unidad hidrográfica. Esta formación rocosa normalmente aflora en las laderas y en parte está cubierta de material superficial producto de antiguos procesos de erosión glaciar (pleistoceno). Asimismo, compuesto por depósitos derivados de procesos coluviales en laderas (deslizamientos) del cuaternario reciente (holoceno).

Tabla 1. Litología de la unidad hidrográfica de la quebrada Chucumayo

\begin{tabular}{|l|c|l|}
\hline Unidadades & Símbolo & Litología (resumen) \\
\hline Depósitos aluviales & Qr-al & Cantos, gravas y arenas \\
\hline Depósitos glaciares & Qr-g & Depósitos morréricos antiguos \\
\hline Depósitos glaciares & Qpl-g & Depósitos morréricos antiguos \\
\hline Volcánico Pacococha & Ts-p & Derrames volcánicos andesíticos \\
\hline Formación Rímac & Tim-r & $\begin{array}{l}\text { Andesitas, tufo andesíticos, con } \\
\text { ocasionales intercalaciones de } \\
\text { areniscas tufáceas }\end{array}$ \\
\hline
\end{tabular}

Fuente: INGEMMET, Boletín 43, 1992.

Gráfico 2. Geología

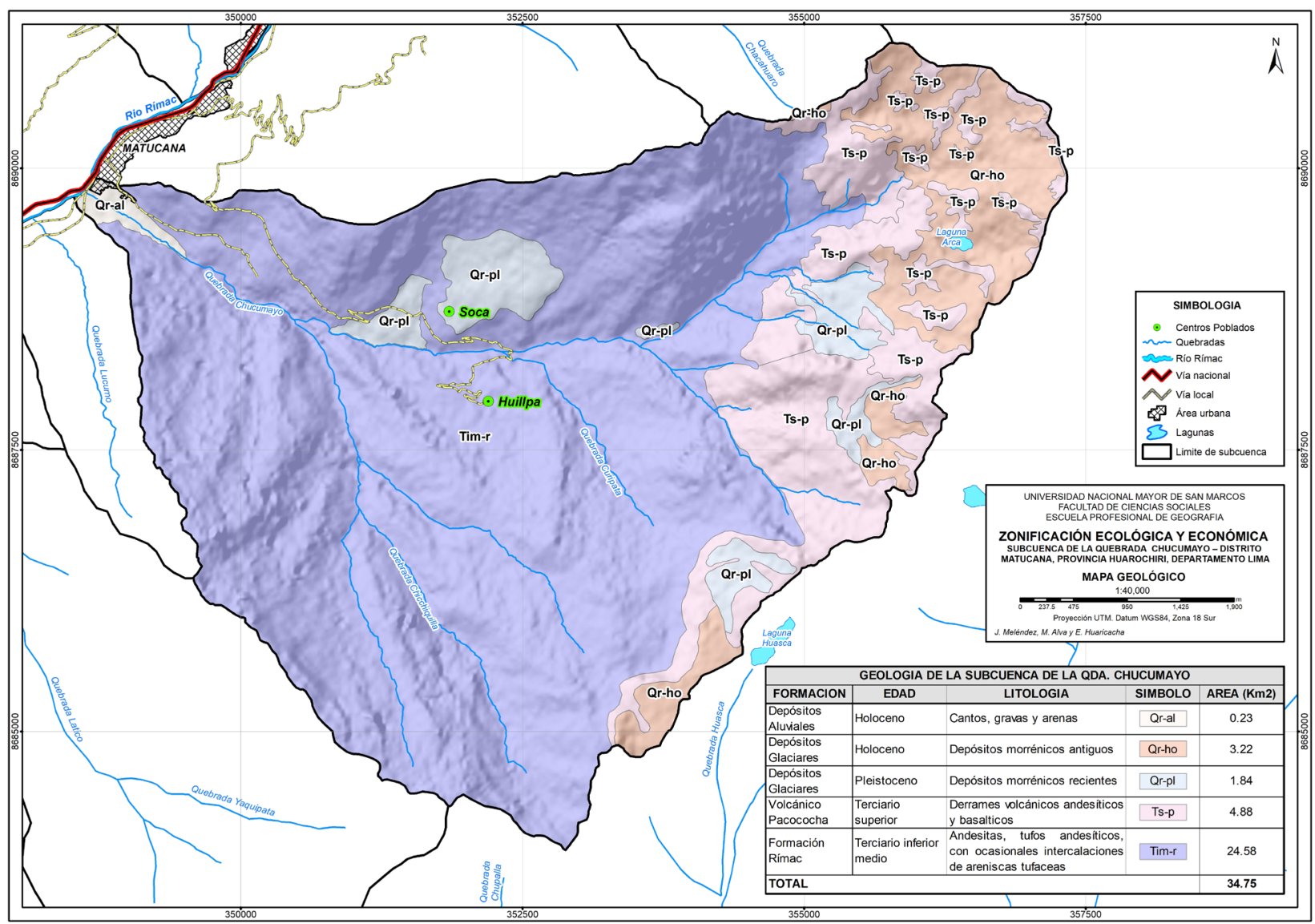

INGEMMET, Boletín 43, 1992. 


\section{Geomorfología}

\section{Geomorfología regional}

En el contexto general la unidad hidrográfica de la quebrada Chucumayo se localiza en la vertiente Occidental de la Cordillera de los Andes, conformado por montańas. La litología predominante de la mencionada geoforma es el sustrato volcano-sedimentarias disectados por quebradas de corto recorrido, torrentes y cárcavas. El valle está estructurado por terrazas aluvionales y en la desembocadura de la quebrada se aprecia un pequeńo cono deyectivo de forma deltaica.

\section{Geomorfología a nivel local}

La geoforma más recurrente en el área de estudio es la montańa con laderas que tienen declives de muy inclinadas a escarpadas. Las terrazas aluviales normalmente se localizan en la parte baja de la subcuenca. Las unidades que contiene el mapa geomorfológico se han clasificado considerando el método thalweg (zonas de valle) e interfluvio (laderas de montańas).

\section{Clasificación geomorfológica}

Se estableció una clasificación geomorfológica por polígonos acompañado de una tabla de atributos que considera la geología, los declives y los procesos exógenos. Las unidades recurrentes son las ladera de roca volcano-sedimentaria que se diferencian por su topografía y material superficial. Esa clasificación se presenta en la siguiente tabla.

\section{Pendientes del terreno}

Normalmente, el declive del relieve en los interfluvios supera los $40^{\circ}$. El cono aluvial de la quebrada Chucumayo tiene una pendiente promedio de $3^{\circ}$ a $6^{\circ}$. Las terrazas aluviales tienen escasa inclinación. En los espacios de la parte alta de la subcuenca la pendiente que tiene entre $3^{\circ}$ a $6^{\circ}$ se relaciona con morrenas, mientras que el declive entre $20^{\circ}$ a $10^{\circ}$ se vincula con mesetas. Las geoformas localizadas al pie de las laderas (taludes de derrubios) tienen una pendiente general de $30^{\circ}$. La clasificación de pendientes del terreno se ha diseńado de tal manera

Tabla 2. Geomorfología de la unidad hidrográfica de la quebrada Chucumayo

\begin{tabular}{|c|c|c|}
\hline Unidad geomorfológica & Símbolo & Área $\left(\mathrm{km}^{2}\right)$ \\
\hline Cono proluvial & Con-pr & 0.12 \\
\hline Ladera algo escarpada con material coluvial & Lae-co & 1.26 \\
\hline Ladera algo escarpada de rocas volcano sedimentaria & Lae-vs & 4.42 \\
\hline Ladera algo inclinada de material coluvial & Lai-co & 0.97 \\
\hline Ladera algo inclinada de rocas sedimentaria & Lai-rs & 1.80 \\
\hline Ladera algo inclinada de rocas sedimentaria y depósitos glaciares & Lai-rsg & 2.12 \\
\hline Ladera algo inclinada de rocas volcánica y material coluvial & Lai-vco & 0.78 \\
\hline Ladera algo inclinada de rocas volcano sedimentaria & Lai-vs & 1.99 \\
\hline Ladera escarpada con afloramiento rocoso & Le-ar & 0.94 \\
\hline Ladera escarpada de rocas volcánica y material coluvial & Le-vco & 0.02 \\
\hline Ladera escarpada de rocas volcano sedimentaria & Le-vs & 2.41 \\
\hline Ladera muy escarpada con afloramientos rocosos & Lme-ar & 5.74 \\
\hline Ladera muy escarpada de material coluvial & Lme-co & 0.25 \\
\hline Ladera muy escarpada de rocas volcánica & Lme-rv & 2.12 \\
\hline Ladera muy escarpada de rocas volcano sedimentaria & Lme-vs & 3.66 \\
\hline Ladera muy inclinada de rocas volcano sedimentaria & Lmi-vs & 0.56 \\
\hline Lecho menor rocoso & 1-roc & 0.08 \\
\hline Meseta & Mes-g & 1.90 \\
\hline Meseta & Mes-v & 0.31 \\
\hline Planicie glaciar & Pla-g & 0.25 \\
\hline Talud de derrubios & Tal-vg & 2.24 \\
\hline Talud y cono de derrubios & Tal-cd & 0.24 \\
\hline Terrazas proluviales & T-pr & 0.10 \\
\hline Torrente con laderas volcano sedimentarias muy disectadas & Tor-vs & 0.46 \\
\hline \multicolumn{2}{|l|}{ Total } & 34.75 \\
\hline
\end{tabular}


Gráfico 3. Geomorfología

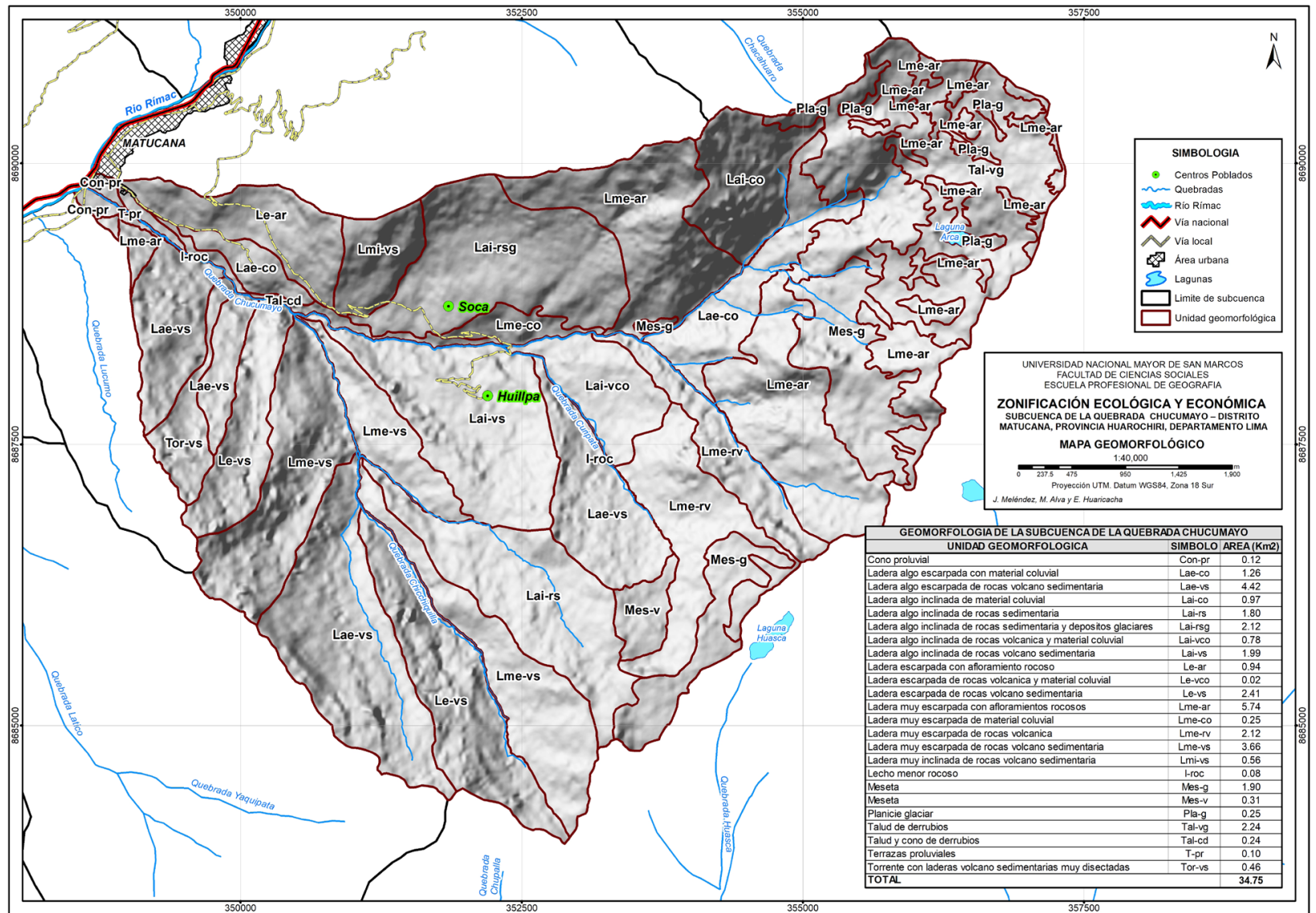

Elaboración propia.

que coadyuve a relacionar las formas del relieve con procesos geomórficos.

Tabla 3. Pendientes del terreno de la unidad hidrográfica de la quebrada Chucumayo

\begin{tabular}{|l|c|c|}
\hline Cualidad & Rango & Área $\mathbf{k m}^{2}$ \\
\hline Muy escarpado & $>45^{\circ}$ & 12.40 \\
\hline Escarpado & $45^{\circ}-40^{\circ}$ & 5.55 \\
\hline Algo escarpado & $40^{\circ}-30^{\circ}$ & 9.60 \\
\hline Muy inclinado & $30^{\circ}-25^{\circ}$ & 2.30 \\
\hline Inclinado & $25^{\circ}-20^{\circ}$ & 0.35 \\
\hline Algo inclinado & $20^{\circ}-10^{\circ}$ & 4.48 \\
\hline Moderadamente ondulado & $10^{\circ}-3^{\circ}$ & 0.05 \\
\hline Suave & $3^{\circ}-1^{\circ} 30^{\circ}$ & 0.01 \\
\hline Llano Total & $<1^{\circ} 30^{\circ}$ & 0.01 \\
\hline \multicolumn{2}{|c|}{} & 34.75 \\
\hline
\end{tabular}

Elaboración propia.

\section{Variables climáticas}

Las características climáticas en la unidad hidrográfica de interés están diferenciadas por las altitudes. En general el clima de la subcuenca es semiárido, es decir, las lluvias son escasas durante el año. Las precipitaciones en promedio anuales en la subcuenca se distribuyen de la siguiente manera: en zonas aledańas al nivel de base de la unidad hidrográfica tiene 200 $\mathrm{mm}$, en la parte media $350 \mathrm{~mm}$ y en los espacios de cabecera tiene $500 \mathrm{~mm}$. El periodo de lluvias se inicia en setiembre (inicio del año hidrológico) con máximas precipitaciones entre los meses de diciembre y abril. La temperatura promedio anual es $16^{\circ} \mathrm{C}$. Los extremos de temperatura durante el día varían entre $6^{\circ}$ a $16^{\circ}$.

\section{Vegetación natural}

La vegetación es un indicador de las condiciones ecológicas y muestra una diferenciación dentro de la unidad hidrográfica. En zonas aledañas al cono de- 


\section{Gráfico 4. Pendientes del terreno}

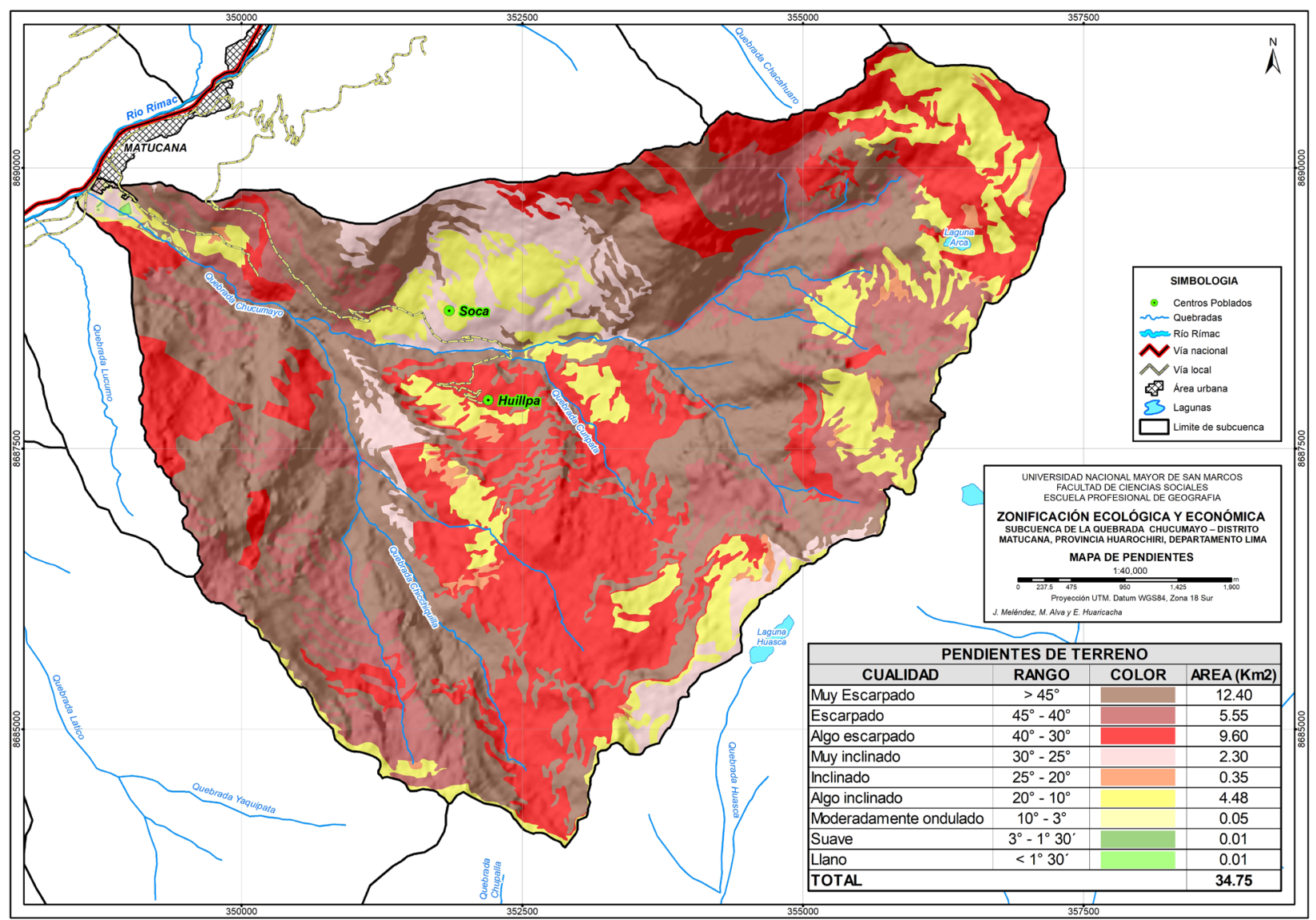

Elaboración propia

Tabla 4. Vegetación en la unidad hidrográfica de la quebrada Chucumayo

\begin{tabular}{|l|c|c|}
\multicolumn{4}{|c}{ quebrada Chucumayo } \\
\hline Vegetación & Símbolo & Área $\left(\mathrm{km}^{2}\right)$ \\
\hline Asociaciones ribereñas & Aso-Riber & 0.03 \\
\hline Bofedales & Bof & 1.36 \\
\hline Bosque de eucalipto & Bos-euc & 0.12 \\
\hline Matorral espinoso & Mat-Esp & 10.46 \\
\hline Matorrales & Mat & 2.81 \\
\hline Pajonal andino & Paj & 16.12 \\
\hline Terrenos de cultivo & Tr-C & 3.82 \\
\hline Ubano & Urb & 0.03 \\
\hline \multicolumn{2}{|c|}{ Total } & 34.75 \\
\hline
\end{tabular}

Elaboración propia.

yectivo de la quebrada (terrazas aluviales) se localizan comunidades vegetales ribereñas tipo herbáceas. En las laderas normalmente se encuentran los matorrales y en muchos tramos han sido transformados con la construcción de terrazas agrícolas (andenería). Por ejemplo, en los espacios aledaños al poblado de Socas, donde se encuentran terrenos de cultivos como: flores, alfalfa, habas, quinua y cebada.

\section{Uso de suelo actual}

En el contexto de la expansión urbana de la localidad de Matucana, hay una tendencia a urbanizar el cono deyectivo y las terrazas aluviales de la quebrada Chucumayo. Cabe agregar, que los años 1959 y 1983 ocurrieron desastres en la localidad de Matucana, impactando las terrazas aluviales del río Rímac. Adicionalmente, en la actualidad la expansión urbana de Matucana se está efectuando sobre laderas, específicamente en los taludes y conos de derrubios localizado al pie de las montañas. De esa manera se van configurando espacios con viviendas y caminos expuestos al impacto de las caídas de rocas y deslizamientos sobre todo por la margen derecha de la mencionada quebrada. Los cambios de uso de suelo que se observa en la parte baja de la subcuenca es el 
Gráfico 5. Vegetación

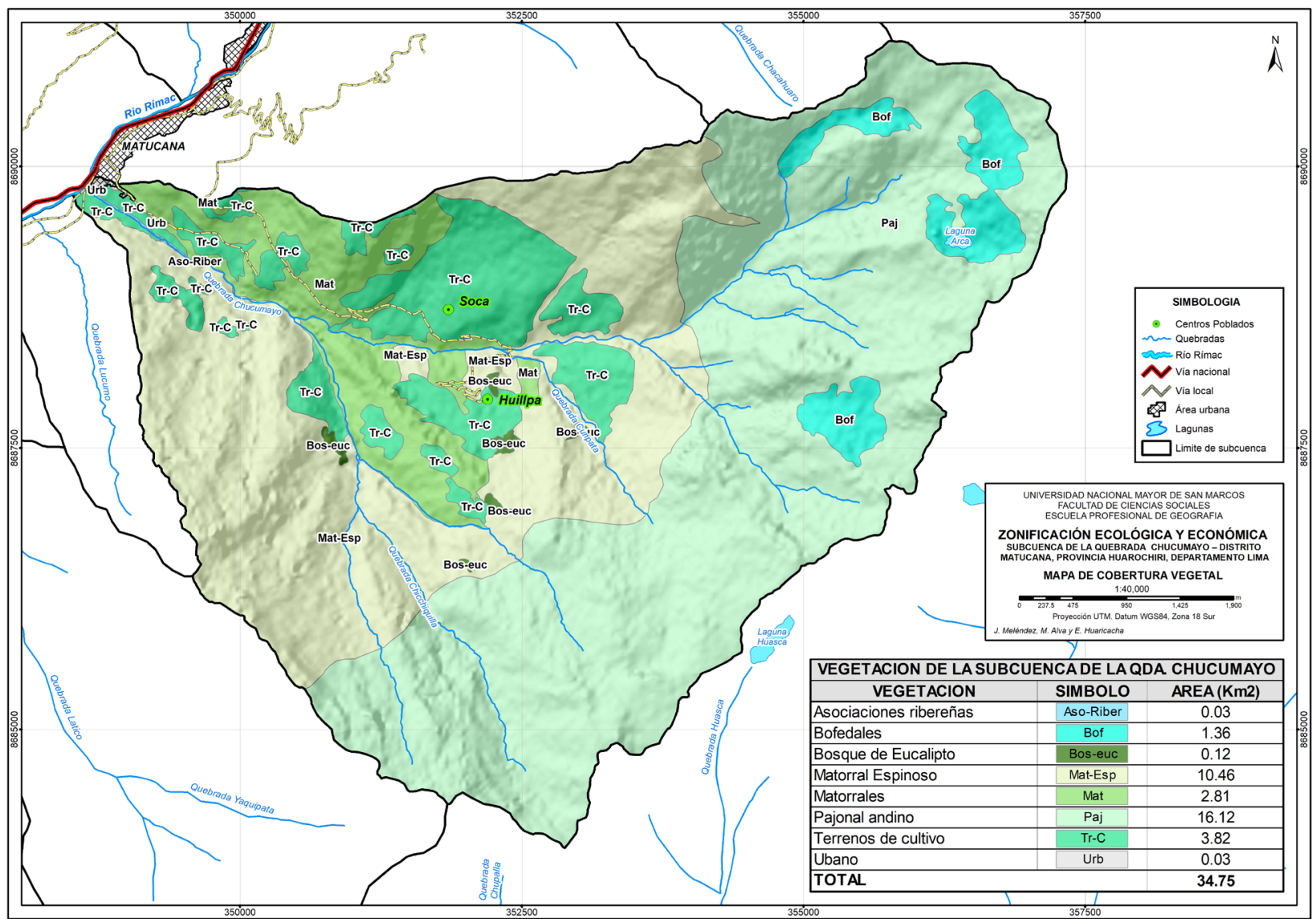

Elaboración propia

resultado del proceso de urbanización. Esa situación es un patrón de ocupación y transformación que se replica en todo el país.

La base económica de gran parte de la unidad hidrográfica de la quebrada Chucumayo se caracteriza por la actividad agrícola desarrollado en pequeñas unidades de producción. En la parte baja de la referida quebrada esas actividades se realizan al borde del lecho menor sin considerar una faja marginal como medida de prevención ante fenómenos de origen natural como aluviones.

En las laderas próximas a la localidad de Matucana también se vienen realizando actividades sobre terrazas agrícolas (andenería) a pesar que los declives de las laderas sobrepasan los $40^{\circ}$. En esas zonas se encuentran suelos de poca profundidad de origen coluvial cubierto de matorrales y se accede mediante caminos muy estrechos sobre laderas muy inclinadas. Las mencionadas laderas tienen altitudes entre los 2400 a 2800 m.s.n.m., se cultivan flores que son trasportados a la ciudad de Lima para su comercialización. También, se pueden señalar otros cultivos como alfalfa, habas, maíz y frutas como níspero y manzanas para el consumo distrital. En las laderas también se pueden encontrar sembríos de tuna y alfalfa.

En áreas aledañas a la cabecera de la unidad hidrográfica de Chucumayo la población se asienta en pequeños centros poblados (Caseríos) como Huiillpa y Soca. En estos espacios por lo general se encuentran rodeado de montañas con declives entre los $20^{\circ}$ y $30^{\circ}$. En los mencionados espacios se desarrollan sembríos mediante terrazas agrícolas (andenería). De igual modo, se encuentran cultivos en espacios ondulados con declives de $10^{\circ}$ a $3^{\circ}$. Los canales de regadío están revestidos por cemento y dotan de agua a las mencionadas actividades. Normalmente, los productos son los siguientes: habas, papas, alfalfa, maíz. 
Tabla 5. Capacidad de uso mayor de suelos

\begin{tabular}{|c|c|c|c|}
\hline Grupo CUM & Clase CUM & Símbolo & Área $\left(\mathrm{km}^{2}\right)$ \\
\hline $\begin{array}{l}\text { Tierras aptas para } \\
\text { Cultivos en Limpio }\end{array}$ & Calidad agrologica baja con limitaciones por suelos, erosión y drenaje & A3sew & 0.18 \\
\hline $\begin{array}{l}\text { Tierras aptas para } \\
\text { Cultivos Permanentes }\end{array}$ & Calidad agrologica baja con limitaciones por suelos, erosión y drenaje & C3sew & 0.01 \\
\hline Tierras aptas para Pastos & Pastos & $\mathrm{P}$ & 8.25 \\
\hline Tierras aptas para Pastos & Calidad agrologica media con limitaciones por suelos y erosión & P2se & 0.00 \\
\hline Tierras aptas para Pastos & Calidad agrologica media con limitaciones por suelos, erosión y drenaje & P2sew & 0.01 \\
\hline Tierras aptas para Pastos & Calidad agrologica baja con limitaciones por suelo & $\mathrm{P} 3 \mathrm{~s}$ & 0.14 \\
\hline Tierras aptas para Pastos & Calidad agrologica baja con limitaciones por suelos y erosión & P3se & 0.56 \\
\hline Tierras aptas para Pastos & Calidad agrologica baja con limitaciones por suelos, erosión y drenaje & P3sew & 0.05 \\
\hline Tierras aptas para Pastos & $\begin{array}{l}\text { Calidad agrologica baja con limitaciones por suelos y erosión con Tierras } \\
\text { aptas para producción forestal de calidad media con limitaciones por } \\
\text { suelos y erosión }\end{array}$ & P3se-F2se & 0.21 \\
\hline $\begin{array}{l}\text { Tierras aptas de } \\
\text { Producción Forestal }\end{array}$ & Producción Forestal & $\mathrm{F}$ & 3.01 \\
\hline Tierras de Protección & Protección & $\mathrm{X}$ & 22.34 \\
\hline \multicolumn{3}{|c|}{ Total } & 34.75 \\
\hline
\end{tabular}

Elaboración propia.

Gráfico 6. Capacidad de uso mayor de suelo

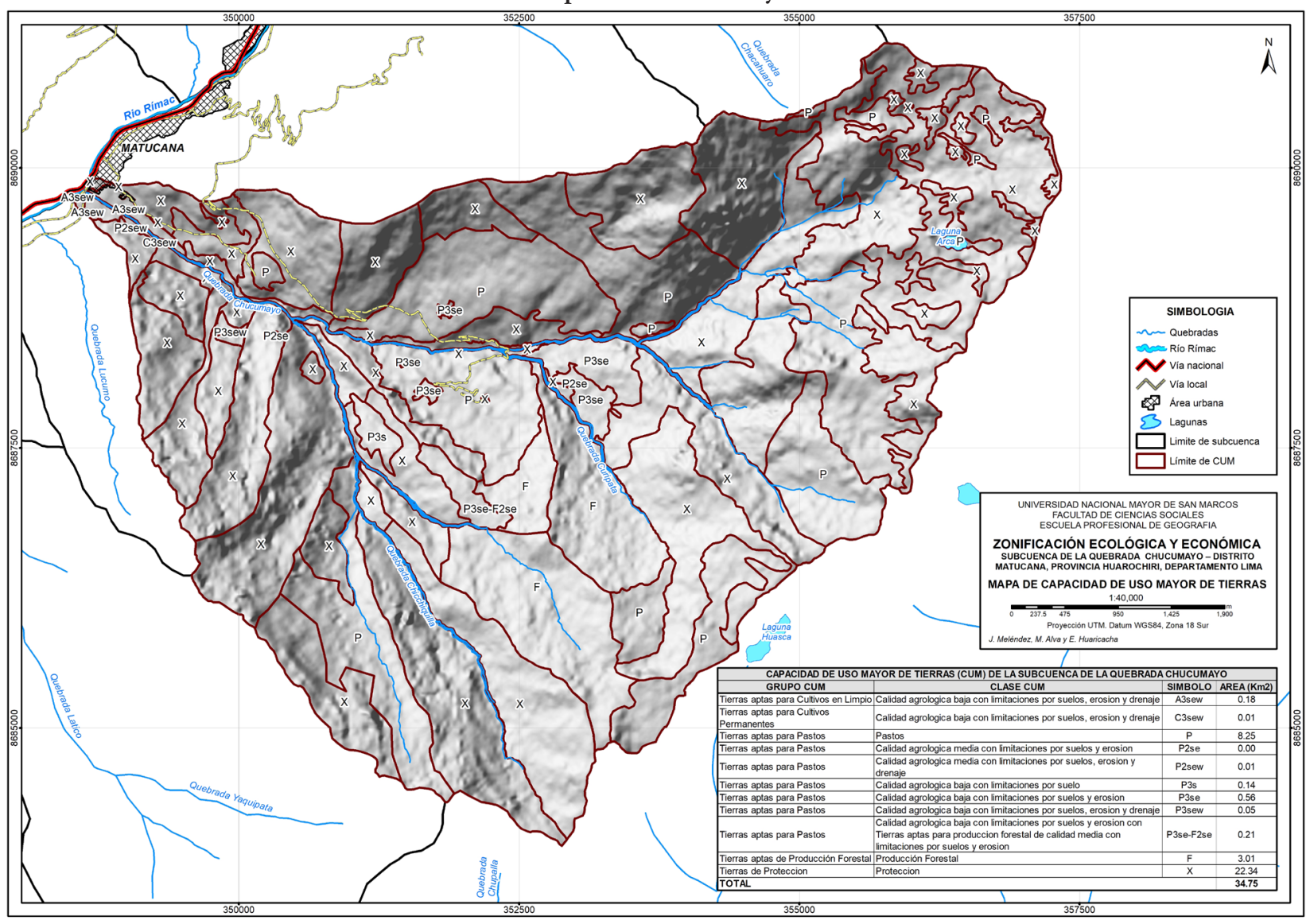

Elaboración propia 
Tabla 6. Usos de suelo o unidades socioeconómicas (USE)

\begin{tabular}{|c|c|c|c|c|c|c|}
\hline Nivel I & Nivel II & Nivel III & Nivel IV & Nivel V & Símbolo & $\begin{array}{l}\text { Área } \\
\left(\mathrm{km}^{2}\right)\end{array}$ \\
\hline \multirow[t]{4}{*}{$\begin{array}{l}\text { Áreas } \\
\text { artificializadas }\end{array}$} & Áreas urbanizadas & $\begin{array}{l}\text { Tejido urbano } \\
\text { continuo }\end{array}$ & & & 1.1 .1 & 0.02 \\
\hline & & $\begin{array}{l}\text { Tejido urbano } \\
\text { discontinuo }\end{array}$ & & & 1.1 .2 & 0.03 \\
\hline & $\begin{array}{l}\text { Áreas industriales e } \\
\text { infraestructura }\end{array}$ & $\begin{array}{l}\text { Red vial, ferroviaria y } \\
\text { terrenos asociados }\end{array}$ & $\begin{array}{l}\text { Red vial y terrenos } \\
\text { asociados }\end{array}$ & Carretera & 1.2.2.1.1 & 0.01 \\
\hline & & & & Caminos & 1.2.2.1.2 & 0.05 \\
\hline \multirow[t]{7}{*}{ Áreas agrícolas } & Cultivos transitorios & $\begin{array}{l}\text { Cultivos de } \\
\text { leguminosas }\end{array}$ & Cultivos de alfalfa & & 2.1.1.1 & 1.18 \\
\hline & & Cultivos ornamentales & Cultivo de flores & & 2.1 .2 .1 & 0.13 \\
\hline & & $\begin{array}{l}\text { Otros cultivos } \\
\text { transitorios }\end{array}$ & & & 2.1 .3 & 0.35 \\
\hline & & $\begin{array}{l}\text { Cultivos transitorios } \\
\text { en descanso }\end{array}$ & & & 2.1 .4 & 1.38 \\
\hline & Cultivos permanentes & $\begin{array}{l}\text { Cultivos permanentes } \\
\text { arbóreos }\end{array}$ & Cultivos frutales & & 2.2 .3 .1 & 0.03 \\
\hline & & Cultivos agroforestales & $\begin{array}{l}\text { Pastos y árboles } \\
\text { plantados }\end{array}$ & & 2.2.4.1 & 0.10 \\
\hline & $\begin{array}{l}\text { Áreas agrícolas } \\
\text { heterogéneas }\end{array}$ & Mosaico de cultivos & & & 2.4 .1 & 1.20 \\
\hline \multirow{6}{*}{$\begin{array}{l}\text { Bosques y áreas } \\
\text { mayormente } \\
\text { naturales }\end{array}$} & Bosques plantados & Bosques de eucaliptos & & & 3.2 .1 & 0.10 \\
\hline & $\begin{array}{l}\text { Áreas con vegetación } \\
\text { herbácea y/o } \\
\text { arbustiva }\end{array}$ & Arbustal & Arbustal denso & & 3.3.2.1 & 0.06 \\
\hline & & $\begin{array}{l}\text { Vegetación arbustiva/ } \\
\text { herbácea }\end{array}$ & $\begin{array}{l}\text { Vegetación herbácea } \\
\text { arbustiva abierta }\end{array}$ & & 3.3 .4 .2 & 3.88 \\
\hline & & & $\begin{array}{l}\text { Vegetación herbácea } \\
\text { arbustiva densa }\end{array}$ & & 3.3 .4 .3 & 9.57 \\
\hline & $\begin{array}{l}\text { Áreas sin o poca } \\
\text { vegetación }\end{array}$ & Afloramiento rocoso & & & 3.4 .2 & 4.50 \\
\hline & & $\begin{array}{l}\text { Tierras desnudas o } \\
\text { degradadas }\end{array}$ & & & 3.4 .3 & 11.03 \\
\hline Áreas húmedas & $\begin{array}{l}\text { Áreas húmedas } \\
\text { continentales }\end{array}$ & Turberas y bofedales & Bofedales & & 4.1 .2 .1 & 0.73 \\
\hline \multirow[t]{5}{*}{$\begin{array}{l}\text { Superficies de } \\
\text { agua }\end{array}$} & Aguas continentales & Ríos y quebradas & Ríos & $\begin{array}{l}\text { Lecho mayor } \\
\text { de río }\end{array}$ & 5.1.1.1.1 & 0.00 \\
\hline & & & Quebradas & Quebrada & 5.1.1.2.1 & 0.25 \\
\hline & & & & Cácava & 5.1.1.2.2 & 0.08 \\
\hline & & $\begin{array}{l}\text { Lagunas, lagos y } \\
\text { ciénagas naturales }\end{array}$ & Laguna & & 5.1 .2 .1 & 0.04 \\
\hline & & $\begin{array}{l}\text { Cuerpos de agua } \\
\text { artificiales }\end{array}$ & Reservorio de agua & & 5.1.5.1 & 0.00 \\
\hline \multicolumn{6}{|c|}{ Total } & 34.75 \\
\hline
\end{tabular}

Elaboración propia. 
Clasificación de usos mayor de suelo (CUM)

La capacidad de uso mayor de suelo (CUM) se ha preparado tomando en cuenta el procedimiento establecido en el Reglamento de Clasificación de Tierras por su Capacidad de Uso Mayor (CUM) aprobado mediante el Decreto Supremo No 017-2009-AG el 01 de setiembre de 2009. La obtención de las características edáficas del suelo se realizó en el campo mediante calicatas, con base en las propiedades físicas en las zonas más relevantes de la unidad hidrográfica de la quebrada Chucumayo.

En el área de estudio predominan los suelos de protección (64.27\%), es decir, no es recomendable su uso porque su potencial productivo es escaso, adicionalmente generaría problemas de erosión, cárcavas, etc.

El 26.21\% del área total de la unidad hidrográfica es apta para pastos naturales o se podría adaptar a la mencionada actividad, las cuales no requieren remoción constante del suelo ni cuidados permanentes ni aplicación de agroquímicos. Las mencionadas tierras también podrían destinarse a la agroforestería, según las demandas.

En tanto que las tierras con posibilidad para establecer cultivos en limpio y para cultivos permanentes, son pocas y tienen limitaciones por suelo, erosión y drenaje. El resumen de la Capacidad de uso mayor de suelos de la unidad hidrográfica se presenta en la tabla 15 .

\section{Zonificación ecológica económica}

\subsection{Metodología}

El modelo de ZEE se ha adaptado a las características ecológicas de la unidad hidrográfica, con base en el conocimiento previo de las limitaciones de los recursos agua y suelo. A continuación, se presenta las características del estudio y el procedimiento seguido para alcanzar los resultados.

\section{Gráfico 7. Unidades ecológicas}

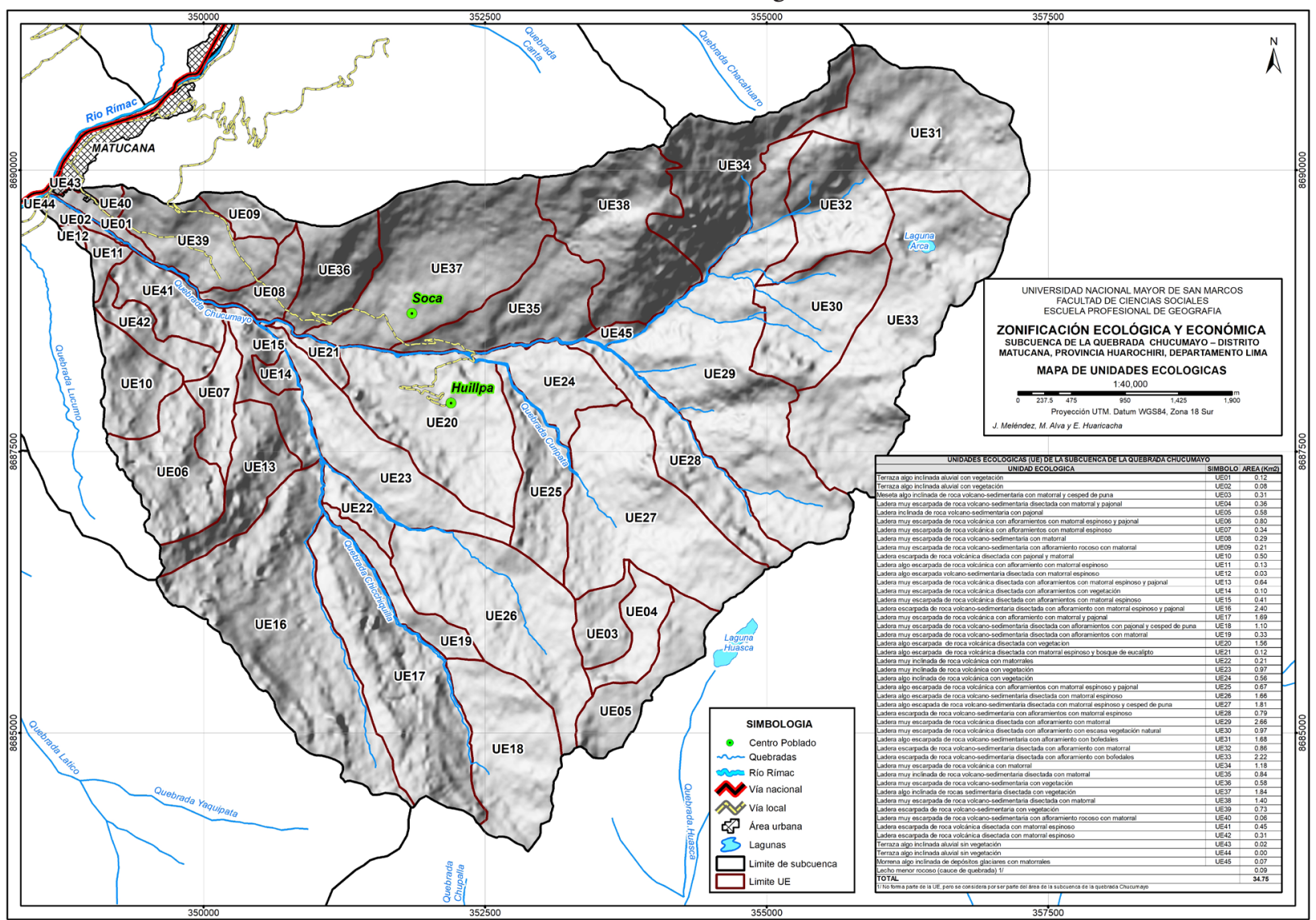

Elaboración propia 
Gráfico 8. Usos de suelo

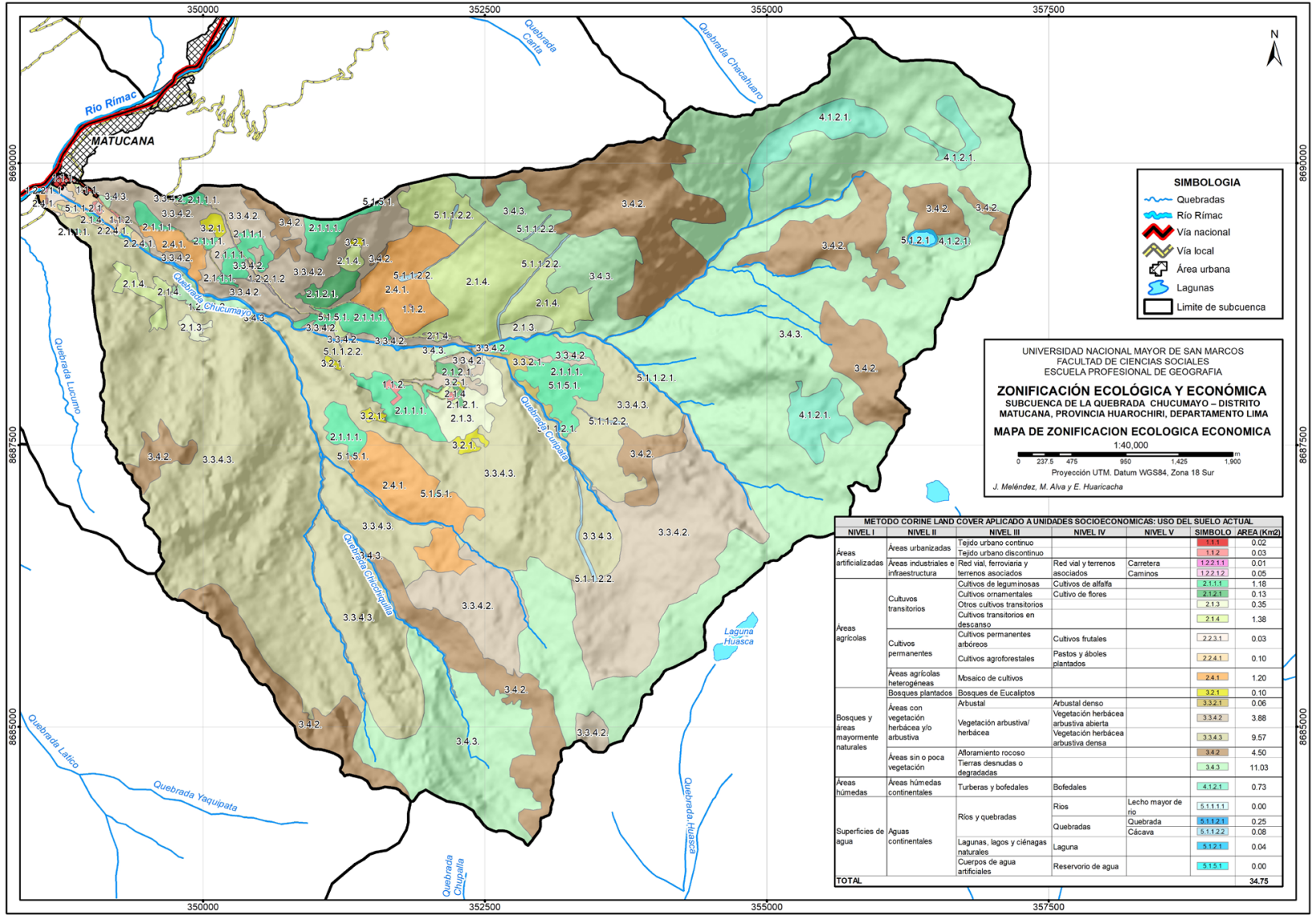

Elaboración propia

A. Características generales

Nivel de estudio: Meso-zonificación ecológica económica

Escala: 1: 100000

Área de estudio: Unidad hidrográfica de la quebrada Chucumayo (subcuenca)

B. Procedimiento

- Descripción temática medio físico. Geología, Geomorfología, pendientes del terreno, vegetación, clima, capacidad de uso mayor del suelo (CUM)

- Descripción temática del medio socioeconómico. Usos de suelo ańos 2014 y 2019.

- Identificación de unidades ecológicas y unidades ecológicas económicas. Esta última se obtuvo delineando unidades por homogeneidad de características ecológicas, ambientales y económicas (usos de suelo). Se explica con mayor precisión en el punto 3.3.
- Evaluación de la aptitud productiva, los conflictos de uso de suelo y el valor bioecológico de cada unidad ecológica económica con apoyo de la capacidad de uso mayor de suelo, la geomorfológica y pendientes del terreno, así como el uso de suelo.

- Delinear las zonas ecológicas económicas con base en los resultados de los puntos anteriores.

\subsection{Unidades ecológicas (UE)}

Las unidades ecológicas se establecieron con base en la distribución de los ecosistemas, para lo cual se conjugó la información geomorfológica y la vegetación. En ese sentido se proyectó los ecosistemas sobre las geoformas. Por ejemplo, las laderas muy inclinadas con matorrales. Asimismo, las interacciones entre los factores del clima, la vegetación y los atributos del 
Gráfico 9. Unidades ecológicas económicas

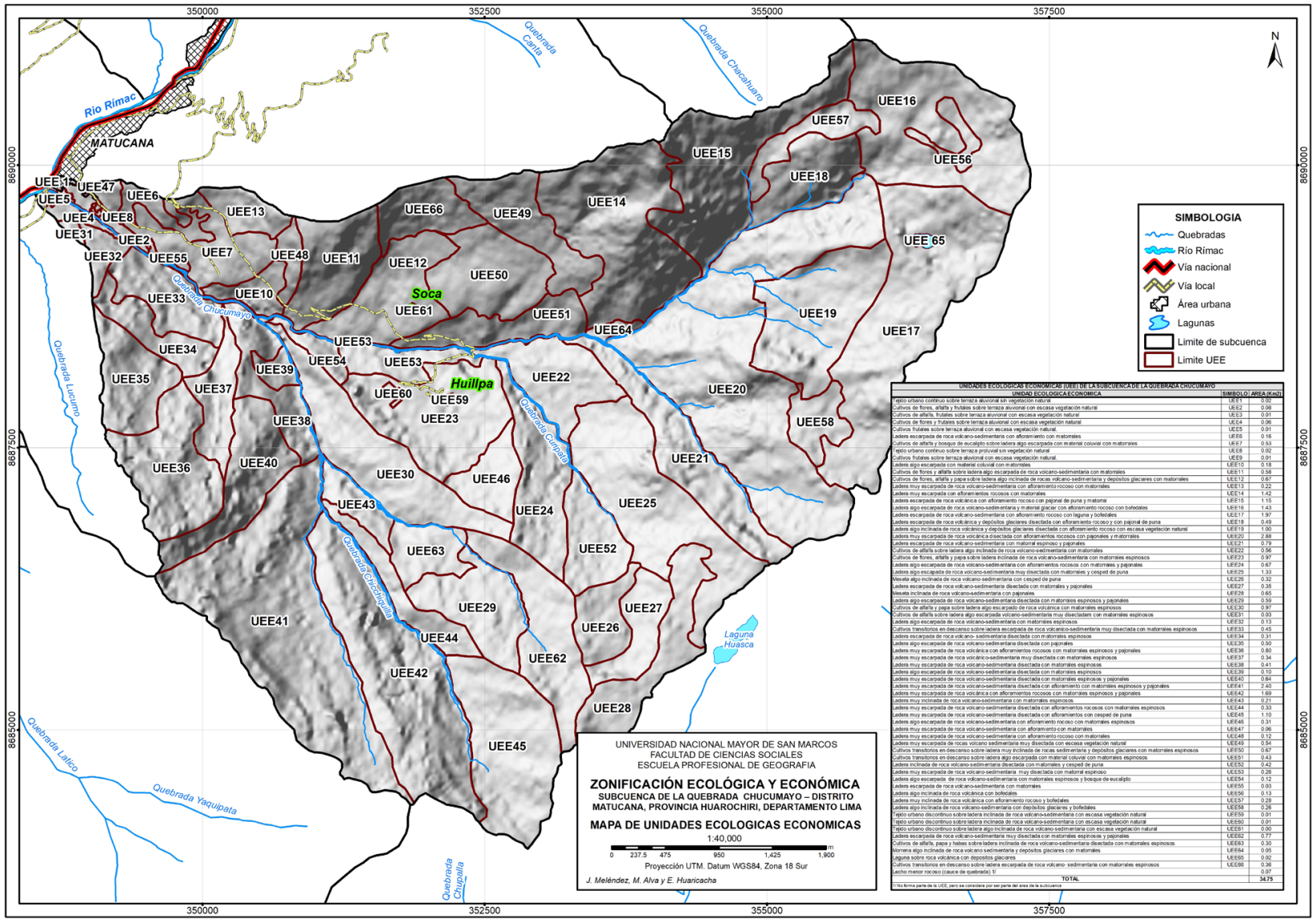

Elaboración propia

relieve como la altitud que se plasman en las zonas de vida.

\subsection{Unidades ecológicas económicas (UEE)}

La tarea para delinear esas unidades consistió en relacionar los aspectos ecológicos con la ocupación. En ese sentido, como trabajo previo se preparó un mapa de unidades socioeconómicas (USE) utilizando el método de Corine Land Cover en el campo y gabinete. Luego, utilizando el enfoque geográfico se relacionó las unidades ecológicas (UE) con las socioeconómicas (USE) obteniéndose las unidades ecológicas económicas (UEE).

Se tiene el antecedente que hace 50 ańos el área de estudio era una mediana productora de alimentos como: hortalizas, leche, carne, etc. Como resultado de la globalización, las generaciones recientes han ido abandonando el campo en busca de las oportunidades que brindan las ciudades. Sin embargo, la pobla- ción que aún reside, en el área de estudio, han encontrado mercados para nuevos productos, por ejemplo: las flores y no hace mucho la cochinilla.

Las zonas de cabecera de cuenca por su geología y geomorfología tienen aptitud para la conservación y para brindar servicios ecosistémicos (por ejemplo, provisión del recurso hídrico). Los suelos coluviales en las laderas han sido artificialmente acondicionados para cultivos, es decir, mediante terrazas agrícolas (andenería). En las partes bajas de la subcuenca donde se lleva a cabo algunas actividades agropecuarias, tienen la ventaja de encontrarse muy cerca de la carretera central para la salida de sus productos hacia grandes mercados como Lima Metropolitana. En la tabla 6 se resume la referida situación.

\section{Propuesta de Zonificación Ecológica Económica}

La propuesta de zonificación ecológica económica fue elaborada con base en la valoración productiva 
Tabla 7. Propuesta de Zonificación Ecológica Económica

\begin{tabular}{|c|c|c|}
\hline Grandes zonas & Zonificación ecológica económica & Área $\left(\mathrm{km}^{2}\right)$ \\
\hline \multirow[t]{5}{*}{ Zonas para producción agropecuaria } & Zonas aptas para cultivos en limpio con calidad agrológica media & 0.12 \\
\hline & $\begin{array}{l}\text { Zonas aptas para cultivos en limpio con calidad agrológica media } \\
\text { asociadas a zonas aptas para cultivo permanente }\end{array}$ & 0.06 \\
\hline & Zonas aptas para pastos & 0.94 \\
\hline & Zonas aptas para pastos con calidad agrológica baja & 1.23 \\
\hline & $\begin{array}{l}\text { Zonas aptas para pastos con calidad agrológica baja asociadas a tierras de } \\
\text { protección }\end{array}$ & 2.52 \\
\hline Zonas de conservación bioecológica & Zonas de conservación bioecológica & 4.50 \\
\hline Zonas de protección & Zonas de protección & 22.78 \\
\hline Zonas de recuperación & Zonas de recuperación & 2.46 \\
\hline Zonas con aptitud urbana & Zonas urbanas & 0.06 \\
\hline \multicolumn{2}{|l|}{ Lecho menor rocoso (cauce de quebrada) } & 0.07 \\
\hline \multicolumn{2}{|r|}{ Total } & 34.75 \\
\hline
\end{tabular}

Elaboración propia.

Gráfico 10. Zonificación ecológica económica

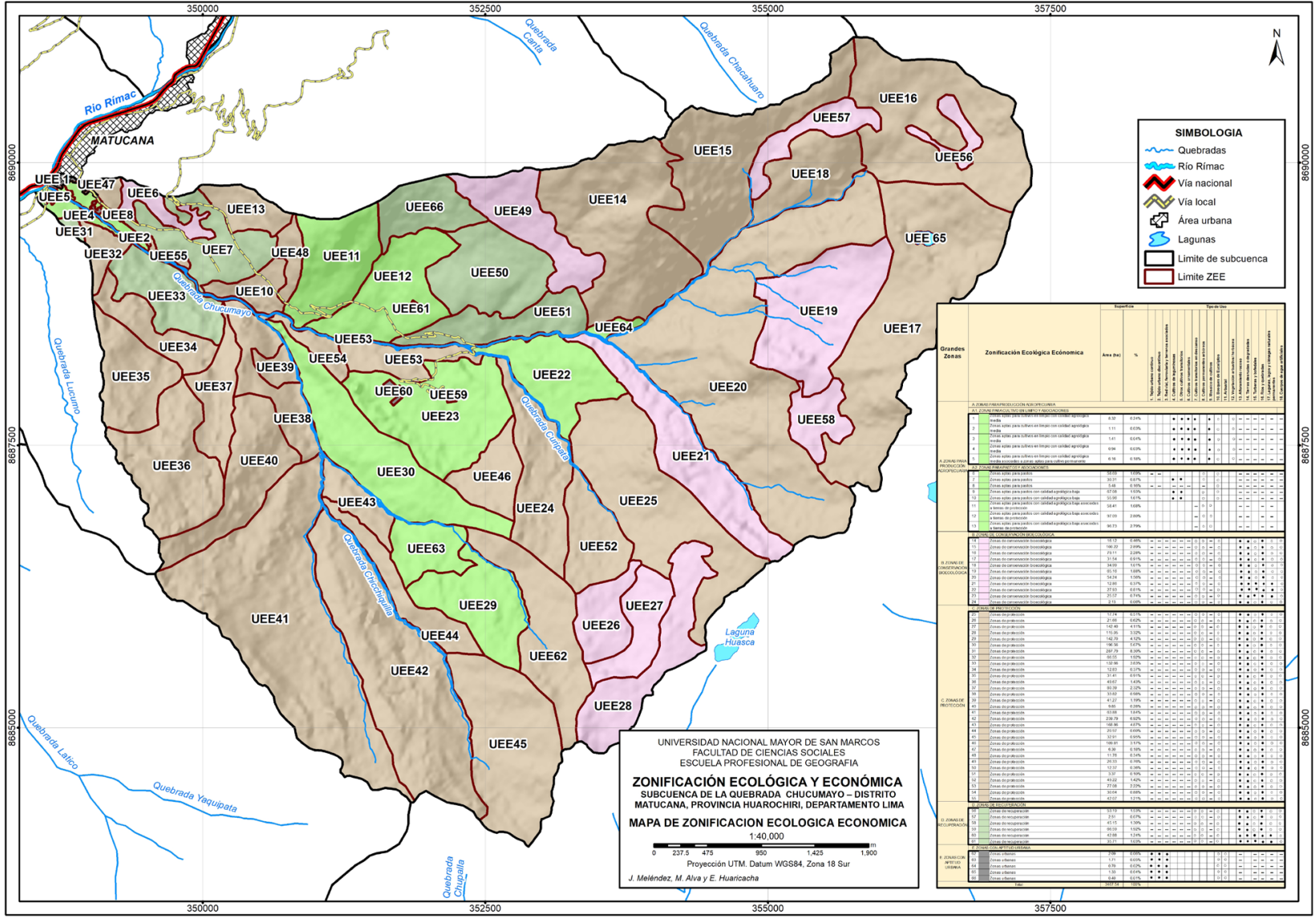

Elaboración propia. 
(zonas productivas), el valor bioecológico (zonas de conservación) y la identificación de los conflictos de uso (zonas de recuperación). En la tabla 7 se resumen el estudio de Zonificación ecológica económica para la unidad hidrográfica.

Se obtuvieron 66 zonas ecológicas económicas siguiendo el procedimiento explicado en el punto 3.1.1, cada una de ellas representa una propuesta de uso de suelo considerando los criterios ecológicos de sostenibilidad, así como el uso racional del territorio y los recursos naturales. La mencionada propuesta se ha hecho llegar oportunamente a las autoridades de la Municipal Provincial de Huarochirí para que pueda ser tomado en cuenta en un eventual proceso de planificación física o de ordenamiento territorial. Los trabajos de estas características se convierten en un insumo técnico y académico en el contexto de los esfuerzos de ordenamiento territorial que se vienen desarrollando en nuestro país.

\section{Conclusiones}

El resultado de la Zonificación Ecológica Económica para el área de estudio es la siguiente: zonas productivas o agropecuarias, $14.04 \%$, zonas de recuperación $7.08 \%$ y de protección $65.5 \%$.
En la unidad hidrográfica de la quebrada Chucumayo predominan las unidades de protección mientras que las áreas agropecuarias son escasas, en razón a que el área de estudio se enmarca en los ecosistemas de montaña.

Una actividad productiva alternativa a ser evaluado sería la forestal cuyo manejo no requiere la asistencia permanente del agricultor.

Los espacios para protección podrían brindan servicios ecosistemas y favorecer las actividades turísticas y de investigación científica. Asimismo, esas actividades contribuirían a preservar el carácter ecológico del área de estudio.

\section{Referencias bibliográficas}

INGEMMET (1992). «Geología de los cuadrángulos de Matucana y Huarochirí». Boletín 43. Lima.

MelÉndez, J; Alva, M. (2016). «Aplicaciones de la geomática para estudios sobre el medio físico y la planificación en la subcuenca de la quebrada Chucumayo. Distrito Matucana, provincia Huarochirí, departamento de Lima». Investigaciones Sociales, Vol. 20, $\mathrm{N}^{\circ} 36$, pp. 95-104.

PREDES (1984). Estudio de seguridad fisica contra huaycos, desbordes y deslizamientos: distrito de Matucana, provincia de Huarochiri, departamento Lima. 